\title{
Influence of Nd:YAG Laser on the Bond Strength of Self-etching and Conventional Adhesive Systems to Dental Hard Tissues
}

\author{
AK Marimoto $\bullet$ LA Cunha $\bullet$ KCK Yui \\ MFRL Huhtala • DC Barcellos • A Prakki \\ SEP Gonçalves
}

\section{Clinical Relevance}

The application of Nd:YAG laser prior to photopolymerization of adhesive systems in an attempt to create a new bonding layer by dentin/adhesive melting significantly increased the shear bond strength to the dentin substrate.

Angela Kimie Marimoto, DDS, MS,GAPEC (Academic Group of Clinical Research) member, Department of Restorative Dentistry, São José dos Campos School of Dentistry, UNESPUniv Estadual Paulista, São Paulo, Brazil.

Lia Alves Cunha, DDS, MS, PhD, GAPEC (Academic Group of Clinical Research) member, Department of Restorative Dentistry, São José dos Campos School of Dentistry, UNESPUniv Estadual Paulista, São Paulo, Brazil.

Karen Cristina Kazue Yui, DDS, MS, PhD, GAPEC (Academic Group of Clinical Research) member, Department of Restorative Dentistry, São José dos Campos School of Dentistry, UNESP- Univ Estadual Paulista, São Paulo, Brazil.

Maria Filomena Rocha Lima Huhtala, DDS, MS, PhD, assistant professor, Department of Restorative Dentistry, São José dos Campos School of Dentistry, UNESP- Univ Estadual Paulista, Brazil.

Daphne Câmara Barcellos, DDS, MS, postgraduate student and GAPEC (Academic Group of Clinical Research) member, Department of Restorative Dentistry, São José dos Campos School of Dentistry, UNESP- Univ Estadual Paulista, São Paulo, Brazil.

\section{SUMMARY}

Purpose: The aim of this study was to investigate the influence of Nd:YAG laser on the shear bond strength to enamel and dentin of total and self-etch adhesives when the laser was applied over the adhesives, before they were

Anuradha Prakki, professor, DDS, MS, PhD, Department of Restorative Dentistry, University of Toronto, Toronto, Canada.

*Sérgio Eduardo de Paiva Gonçalves, DDS, MS, PhD, coordinator of GAPEC and associate professor, Department of Restorative Dentistry, São José dos Campos School of Dentistry, UNESP- Univ Estadual Paulista, São Paulo, Brazil.

*Corresponding author: Avenida Engenheiro Francisco José Longo, 777, Jardim São Dimas, São José dos Campos, SP, Brazil, CEP: 12245-000; e-mail: sergio@fosjc.unesp.br DOI: $10.2341 / 11-383-\mathrm{L}$ 
photopolymerized, in an attempt to create a new bonding layer by dentin-adhesive melting.

Material and Methods: One-hundred twenty bovine incisors were ground to obtain flat surfaces. Specimens were divided into two substrate groups $(n=60)$ : substrate $E$ (enamel) and substrate D (dentin). Each substrate group was subdivided into four groups $(n=15)$, according to the surface treatment accomplished: $X$ (Xeno III self-etching adhesive, control), XL (Xeno III + laser Nd:YAG irradiation at $140 \mathrm{~mJ} / 10 \mathrm{~Hz}$ for 60 seconds + photopolymerization, experimental), $\mathrm{S}$ (acid etching + Single Bond conventional adhesive, Control), and SL (acid etching + Single Bond + laser Nd:YAG at $140 \mathrm{~mJ} / 10 \mathrm{~Hz}$ for 60 seconds + photopolymerization, experimental). The bonding area was delimited with 3 -mm-diameter adhesive tape for the bonding procedures. Cylinders of composite were fabricated on the bonding area using a Teflon matrix. The teeth were stored in water at $37^{\circ} \mathrm{C} / 48 \mathrm{~h}$ and submitted to shear testing at a crosshead speed of 0.5 $\mathrm{mm} / \mathrm{min}$ in a universal testing machine. Results were analyzed with three-way analysis of variance (ANOVA; substrate, adhesive, and treatment) and Tukey tests $(\alpha=0.05)$. ANOVA revealed significant differences for the substrate, adhesive system, and type of treatment: lased or unlased $(p<0.05)$. The mean shear bond strength values (MPa) for the enamel groups were $\mathrm{X}=\mathbf{2 0 . 2} \pm \mathbf{5 . 6 1}, \mathrm{XL}=\mathbf{2 3 . 6} \pm$ 4.92, $\mathrm{S}=20.8 \pm$ 4.55, $\mathrm{SL}=22.1 \pm \mathbf{5 . 1 4}$ and for the dentin groups were $\mathrm{X}=14.1 \pm 7.51, \mathrm{XL}=22.2 \pm$ 6.45, $\mathrm{S}=11.2 \pm$ 5.77, $\mathrm{SL}=15.9 \pm 3.61$. For dentin, Xeno III self-etch adhesive showed significantly higher shear bond strength compared with Single Bond total-etch adhesive; Nd:YAG laser irradiation showed significantly higher shear bond strength compared with control (unlased).

Conclusion: Nd:YAG laser application prior to photopolymerization of adhesive systems significantly increased the bond strength to dentin.

\section{INTRODUCTION}

The basic mechanism of bonding to enamel and dentin is essentially an exchange process involving replacement of minerals removed from the hard dental tissue as a result of acid etching by resin monomers. When these set, they become micro- mechanically interlocked in the porosities thus created. $^{1}$

Conventional adhesive systems are based on acid etching followed by a conditioning step with the primer and the application of the adhesive resin, or systems that combine the primer and the bonding agent into one application. ${ }^{2}$ In 1994, Watanabe introduced the self-etching adhesive systems, which use nonrinse acidic monomers that simultaneously condition and prime dentin. ${ }^{3}$ However, their low acid concentration and high hydrophilicity promote low bond strength values to enamel substrate, thin hybrid layers, and doubtful marginal sealing. ${ }^{3}$

Today, laser technology is being widely applied in clinical trial procedures. In 1999, Gonçalves and others ${ }^{4}$ developed a technique for Nd:YAG laser application to dentin substrates. This technique consisted of irradiating the dentin substrate with Nd:YAG laser after etching it with phosphoric acid and applying the bonding agent. After this, the adhesive is polymerized. Gonçalves and others ${ }^{4}$ explained that Nd:YAG laser promoted fusion and recrystallization of dentinal hydroxyapatite in the presence of resin monomers, thereby developing a new layer of dentin tissue and adhesive system joined by the action of the laser (ie, a mechanically intermingled substrate that was chemically receptive to bonding). ${ }^{3}$

Although most researchers have found significantly higher bond strength values for adhesive systems that received Nd:YAG irradiation prior to polymerization, most of the studies investigated total-etch adhesives bonded to dentin. ${ }^{4-6}$ The influence of laser irradiation on self-etch adhesives has not yet been adequately evaluated, especially on enamel.

Thus, the aim of this study was to evaluate in vitro the influence of Nd:YAG laser on the shear bond strength to enamel and dentin of a two-step totaletch adhesive and one-step self-etch adhesives when the laser was applied over the adhesives. The null hypothesis tested was that Nd:YAG laser irradiation would not affect the bond strength of the adhesive systems to enamel and dentin substrates.

\section{MATERIALS AND METHODS}

\section{Sample Preparation}

One hundred twenty extracted bovine incisors were cleaned with a scalpel and water/pumice slurry in dental prophylactic cups. The teeth were stored in distilled water and frozen at $-18^{\circ} \mathrm{C}$ until use, within a period of less than 28 days. $^{7}$ The roots were sectioned with a low-speed diamond saw, and the 


\begin{tabular}{|lllll|}
\hline Table 1: Surface Conditioning Methods \\
\hline & \multicolumn{4}{c|}{ Grit of Silicone Carbide Paper (/Time) } \\
\cline { 2 - 5 } & $\begin{array}{c}\text { First } \\
\text { Step }\end{array}$ & $\begin{array}{c}\text { Second } \\
\text { Step }\end{array}$ & $\begin{array}{c}\text { Third } \\
\text { Step }\end{array}$ & $\begin{array}{c}\text { Fourth } \\
\text { Step }\end{array}$ \\
\hline Enamel substrate & 400 & $600 / 15 \mathrm{~s}$ & - & - \\
\hline Dentin substrate & 80 & $320 / 15 \mathrm{~s}$ & $400 / 15 \mathrm{~s}$ & $600 / 15 \mathrm{~s}$ \\
\hline
\end{tabular}

pulp was removed using endodontic instruments. An opening was made on the lingual side of the teeth to promote exposure of the pulp chamber.

The teeth were mounted in a silicone matrix with self-curing acrylic resin, with their buccal surface kept above the surface of the mounted blocks. After polymerization, the lingual portions of the mounted teeth were ground in a trimmer using wet 80 -grit sandpaper, until the wax was removed. The pulp chamber opening was used as access to measure the remaining dentin thickness with a caliper ${ }^{8}$.

For the enamel specimens, the buccal portion was ground in a trimmer using wet 400-grit silicon carbide paper in a polishing machine (Politriz, Struers A/S, Copenhagen, Denmark), under water cooling, until the overlying enamel was removed. After this, the specimen was ground again using wet 600 -grit silicon carbide paper for 15 seconds, under constant pressure, to obtain a uniform surface (Table 1).

For the dentin specimens, the buccal portion was ground in a trimmer using wet 80-grit sandpaper until dentin was exposed. Next, the dentin thickness was measured with a caliper, and this was considered the baseline measure. After this, the specimen was ground again until half of the baseline measure was obtained. This was done in a polishing machine using 320- to 600-grit silicon carbide paper for 15 seconds, under constant pressure, to obtain a uniform smear layer (Table 1).

\section{Bonding Procedures}

To delimit the area for adhesive system application, a special Scotchtape Mold (3M ESPE, St Paul, MN, USA) with a standard central hole, $3 \mathrm{~mm}$ in diameter, was placed on each specimen.

One-hundred twenty specimens were divided into two groups: substrate E (enamel) and substrate D (dentin). Each group was divided into four subgroups
( $n=15 /$ subgroup), according to the surface treatment performed:

- Group X (control): The Xeno III self-etch adhesive (Dentsply De Trey GmbH D, Konstanz, Germany) was applied passively for 20 seconds, gently airdried and polymerized for 10 seconds with a light unit (Curing Light XL 3000; 3M ESPE) with power density of $600 \mathrm{~mW} / \mathrm{cm}^{2}$ as measured by a radiometer (Curing Radiometer Model 100, Demetron Research Corporation, Danbury, CT, USA).

- Group XL (experimental): Specimens received the application of Xeno III self-etch adhesive, followed by irradiation with Nd:YAG laser in noncontact mode, scanning for 60 seconds, and light polymerization for 10 seconds.

- Group S (control): Specimens were etched for 15 seconds with $37 \%$ phosphoric acid gel, rinsed, and gently dried with absorbent paper to remove excess water. Two layers of Single Bond 2 total-etch adhesive (3M ESPE) were applied on the surface in a scrubbing motion for 15 seconds. The remaining solvent was evaporated with a brief, mild air blast, and the adhesive was polymerized for 10 seconds.

- Group SL (experimental): The Single Bond 2 totaletch adhesive was applied in the same way as in group $\mathrm{S}$, and the specimens were irradiated with $\mathrm{Nd}$ :YAG laser in noncontact mode, scanning for 60 seconds, followed by light polymerization for 10 seconds.

\section{Treatment with Nd:YAG Laser}

The Nd:YAG laser equipment used in this study was the Laser Pulse Master 600 iQ (American Dental Technologies Inc, Corpus Christi, TX, USA) at a wavelength of $1.064 \mu \mathrm{m}$. The output energy of this laser device was $140 \mathrm{~mJ}$ per pulse, with a pulse repetition rate of 10 pulses per second $(10 \mathrm{~Hz})$ and total energy of $1.4 \mathrm{~W}$. In this study, the laser was fitted with a noncontact tip $320 \mu \mathrm{m}$ in diameter, and the energy density was $1200 \mathrm{~J} / \mathrm{cm}^{2}$ (Table 2). The laser was applied freehand, in noncontact mode, and scanning for 60 seconds. During laser application, the laser tip was at a $90^{\circ}$ angle, perpendicular to the specimen surface, and at a distance of $5 \mathrm{~mm}$ from it. ${ }^{4}$ Self-curing acrylic resin was used to make a device especially for the purpose of maintaining the distance between the laser tip and the enamel and dentin surfaces.

\section{Restoration Placement}

After the surface treatment, a split Teflon mold, with a 3-mm-diameter hole in the middle of it, was 
Table 2: Nd:YAG Laser and Irradiation Parameters Used

\begin{tabular}{|ll|}
\hline \multicolumn{1}{|c|}{ Laser } & Nd:YAG \\
\hline Wavelength & $1.064 \mu \mathrm{m}$ \\
\hline Mean power & $1.4 \mathrm{~W}$ \\
\hline Pulse frequency & $10 \mathrm{~Hz}$ \\
\hline Pulse duration & $100 \mu \mathrm{s}$ \\
\hline Pulse energy & $140 \mathrm{~mJ}$ \\
\hline Energy density & $1200 \mathrm{~J} / \mathrm{cm}^{2}$ \\
\hline
\end{tabular}

adapted to the specimen in order to insert the composite resin. The composite resin (Filtek Z250, $3 \mathrm{M}$ ESPE) was inserted in two increments of about $1.5 \mathrm{~mm}$ each, using a spatula, and each increment was polymerized with a halogen light (Curing Light XL 3000; 3M ESPE) for 20 seconds. After removing the mold, the composite resin cylinder was light polymerized for an additional 60 seconds.

Specimens were immersed in distilled water at $37^{\circ} \mathrm{C}$ for 48 hours. Subsequently, the shear bond strength test was performed in a universal testing machine at a crosshead speed of $0.5 \mathrm{~mm} / \mathrm{min}$ using a 100-kgf load cell (EMIC, São José dos Pinhais, Paraná, Brazil). The bond strength was determined from the highest point on the stress-strain curve measured by the load cell of the testing machine. Results obtained were expressed in $\mathrm{MPa}$.

After the shear bond strength test, the specimens were analyzed under a stereomicroscope (Stemi 2000, Karl Zeiss, Gottingen, Germany) at $20 \times$ magnification. Failures were classified as cohesive failure in composite, cohesive failure in enamel/ dentin, adhesive at the interface, or mixed.

Bond strength data were analyzed by three-way analysis of variance (ANOVA; substrate, adhesive system, and surface treatment-lased or unlased) followed by Tukey test $(\alpha=0.05)$.

\section{Scanning Electron Microscopy (SEM) Examination}

Two teeth from each group were sectioned perpendicularly to the bonding interface. The sections were polished with 2000 and 4000 mesh sheets. Phosphoric acid etchant was applied for 5 seconds and rinsed off with water for 10 seconds. Specimens were

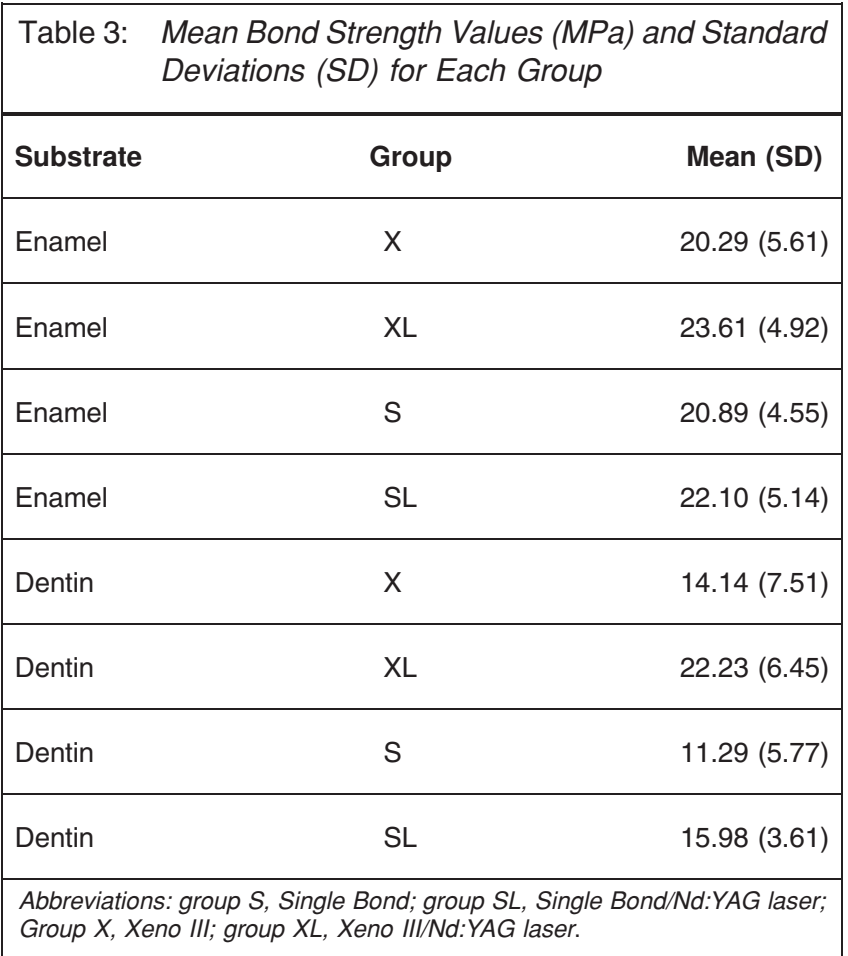

dehydrated, sputter-coated with gold-palladium, and examined using SEM.

\section{RESULTS}

The mean bond strength values in all experimental groups are presented in Table 3 and Figure 1.

ANOVA revealed that enamel substrate presented higher bond strength values compared with dentin substrate $(p=0.000)$, Xeno III adhesive system presented higher bond strength values compared with the Single Bond adhesive system $(p=0.0152)$, and the lased surface treatment presented higher bond strength values compared with unlased surface treatment $(p=0.000)$.

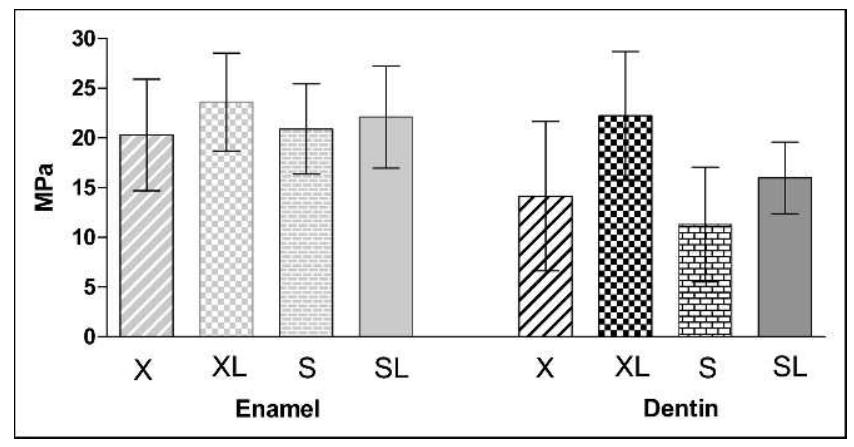

Figure 1. Graph of means and standard deviation (MPa) of bond strength for each group. Group X, Xeno III; group XL, Xeno III/Nd:YAG laser; group S, Single Bond; group SL, Single Bond/Nd:YAG laser. 
Table 4: Tukey Test (5\%) Comparison of Bond Strength Means (MPa) for Adhesive and Substrate ${ }^{a}$

\begin{tabular}{|llr|}
\hline Adhesive & Substrate & Mean \\
\hline Xeno III & Enamel & $21.953^{\mathrm{a}}$ \\
\hline Single Bond & Enamel & $21.501^{\mathrm{ab}}$ \\
\hline Xeno III & Dentin & $18.188^{\mathrm{b}}$ \\
\hline Single Bond & Dentin & $13.635^{\mathrm{c}}$ \\
\hline $\begin{array}{l}\text { a Mean values with the same letters showed no statistically significant } \\
\text { difference. }\end{array}$ & \\
\hline
\end{tabular}

There was significant interaction between the independent variables of "substrate" and "treatment" $(p=0.044)$. Enamel substrate with Xeno III adhesive system $(21.95 \mathrm{MPa})$ presented higher bond strength values compared with dentin substrate, irrespective of the adhesive system tested, and dentin substrate with the Single Bond adhesive system (18.18 MPa) presented the lowest bond strength (Table 4). The Xeno III adhesive system presented higher bond strength values compared with the Single Bond adhesive system, irrespective of the substrate tested (Table 4).

There was significant interaction between the independent variables of "substrate" and "adhesive system" ( $p=0.045)$. Enamel substrate lased ( 22.85 $\mathrm{MPa}$ ) presented higher bond strength values compared with dentin substrate, lased (19.10 $\mathrm{MPa})$ or unlased (12.71 MPa), and irrespective of the adhesive system tested (Table 5). Treatment with Nd:YAG laser prior to photopolymerization of the adhesive systems significantly increased the bond strength to dentin substrate (Table 5).

Three-way ANOVA revealed that the interaction between the three variables was not statistically significant, so the relationship between laser and substrate for the adhesive Xeno III was similar to that for Single Bond (Figure 2).

Examination of specimens after failure indicated predominantly adhesive and mixed failure for all groups, except for group X (Xeno III) without laser (control) in enamel, which showed an almost equal distribution between the four types of failure (Table $6)$.

SEM micrographs of the bonded interface in dentin with Xeno III showed that the control group
Table 5: Tukey Test (5\%) Comparison of Bond Strength Means (MPa) for Substrate and Treatment ${ }^{a}$

\begin{tabular}{|llc|}
\hline Laser & Substrate & Mean \\
\hline Presence & Enamel & $22.858^{\mathrm{a}}$ \\
\hline Absence & Enamel & $20.595^{\mathrm{ab}}$ \\
\hline Presence & Dentin & $19.107^{\mathrm{b}}$ \\
\hline Absence & Dentin & $12.716^{\mathrm{c}}$ \\
\hline $\begin{array}{l}\text { a Mean values with the same letters showed no statistically significant } \\
\text { difference. }\end{array}$ & \\
\hline
\end{tabular}

generally showed a well-developed resin-impregnated zone (hybrid layer; Figure 3). Figure 4 showed that there were more resin tags in the sample on which Nd:YAG laser was applied when compared with the sample in which no irradiation was applied (Figure 3) and the presence of resin tags with welldefined terminations in dentinal tubules.

SEM images showed that in the sample on which no irradiation was applied (Figure 5) and in the sample on which Nd:YAG laser was applied (Figure 6 ), the bond interface between enamel and Xeno III was similar in both treatments.

\section{DISCUSSION}

This study investigated the possible influence of $\mathrm{Nd}$ :YAG laser on the shear bond strength to enamel and dentin of adhesive systems (total etch and selfetch) when the laser was applied over the adhesives, before they were light polymerized, and on the formation of an optimized bonding layer.

Greater difficulty in promoting a satisfactory bond to dentin was observed in this study, in which the bond strength values were lower than those to enamel for both adhesive systems, independent of laser treatment. Although the bond to enamel is usually more effective than to dentin, evaluations in enamel continue to be relevant because the performance of new self-etch adhesive systems show lower bond strength values when compared with conventional systems because of the lower acid concentration. ${ }^{9,10}$

Peumans and others, ${ }^{2}$ in a systematic review of contemporary clinical trials, found an inefficient clinical performance for the most commonly tested one-step self-etch adhesives, Prompt L-Pop (3M 


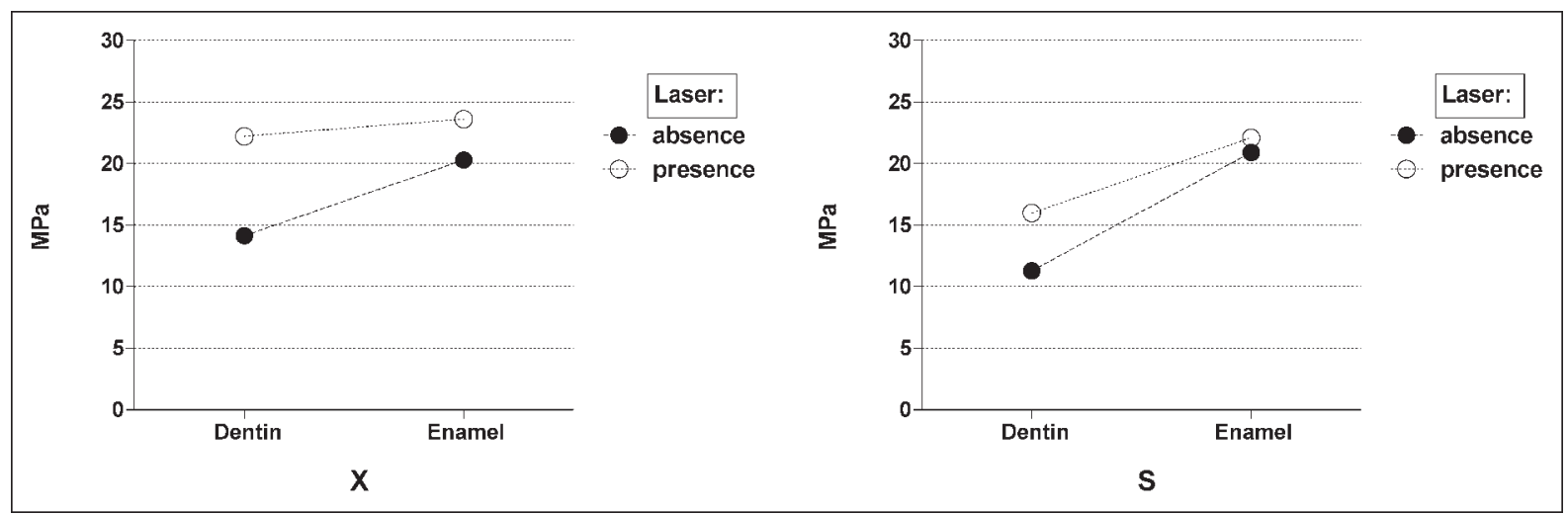

Figure 2. Graph of means showing the interaction between the three variables. X, Xeno III self-etch adhesive; S, Single Bond total-etch adhesive.

ESPE) and PSA (Dentsply-Detrey). They showed the highest average annual failure rate $(8.1 \%)$, and most adhesives failed to meet the American Dental Association Acceptance requirements. ${ }^{2}$

The results of the present research showed the superiority of the self-etching adhesive Xeno III both in enamel and dentin. There was no significant difference between Xeno III and Single Bond in enamel, but it was significant in dentin. On the other hand, Faria-E-Silva and others ${ }^{11}$ showed that the adhesive Xeno III presented lower bond strength to enamel than to dentin and that the best results for this adhesive were in dry substrates. In the study by
Chaves and others, ${ }^{12}$ Xeno III had a good performance in combination with the luting agent Variolink II, with regard to microtensile bond strength after 90 days of storage in water.

The null hypothesis was rejected for dentin substrate because the Nd:YAG laser irradiation significantly increased the bond strength to this substrate. For enamel substrate, the null hypothesis was accepted because the difference was not statistically significant.

The first applications of Nd:YAG lasers for dental surface treatment (before bond application) resulted in a reduction in bond strength when compared with

\begin{tabular}{|c|c|c|c|c|c|c|}
\hline \multirow[t]{2}{*}{ Substrate } & \multirow[t]{2}{*}{ Adhesive } & \multirow[t]{2}{*}{ Laser } & \multicolumn{4}{|c|}{ Failure Mode ${ }^{a}$} \\
\hline & & & A & M & CD & CR \\
\hline Enamel & Single Bond & Absence & 15 & - & - & - \\
\hline Dentin & Xeno III & Absence & 11 & 2 & 2 & - \\
\hline Dentin & Xeno III & Presence & 14 & - & 1 & - \\
\hline Enamel & Single Bond & Presence & 15 & - & - & - \\
\hline Dentin & Single Bond & Presence & 15 & - & - & - \\
\hline Enamel & Xeno III & Presence & 4 & 5 & 6 & - \\
\hline Enamel & Xeno III & Absence & 15 & - & - & - \\
\hline Dentin & Single Bond & Absence & 12 & 3 & - & - \\
\hline
\end{tabular}




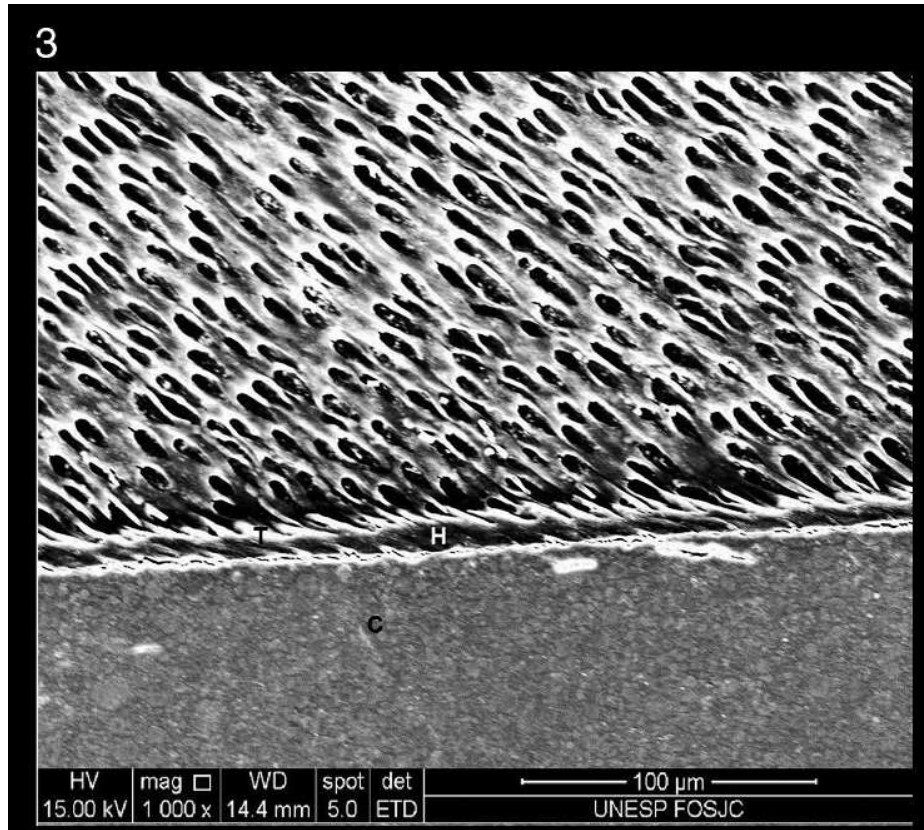

5

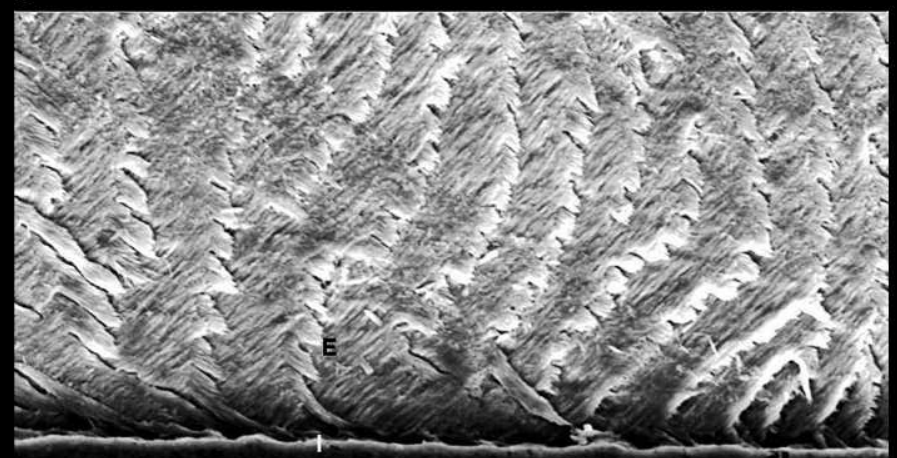

C

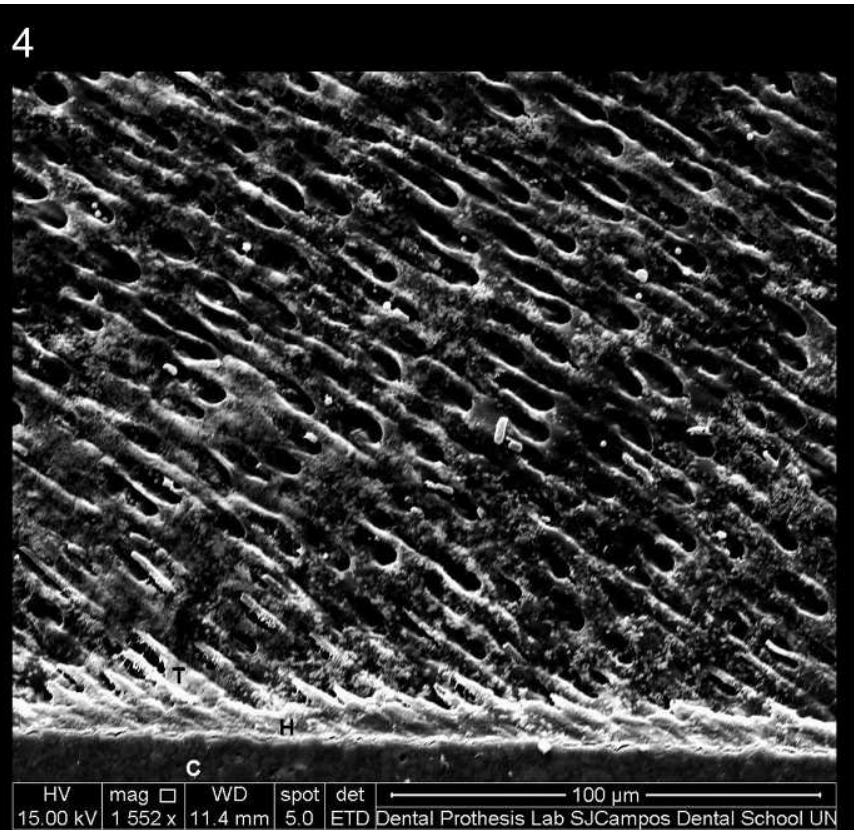

6

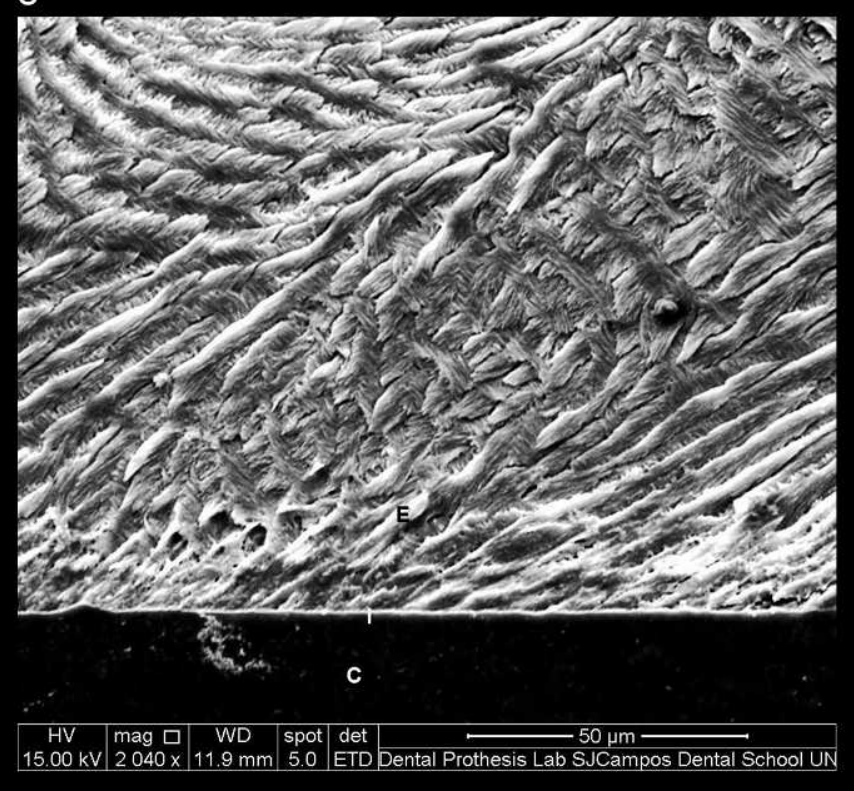

Figure 3. Scanning electron micrograph of the bond interface of the specimen that received dentin treatment according to the manufacturer's instructions (Xeno III self-etch adhesive). C, composite; $H$, hybrid layer; $T$, resin tags.

Figure 4. Scanning electron micrograph of the bond interface of the specimen that received dentin treatment according to the manufacturer's instructions (Xeno III self-etch adhesive) + laser Nd:YAG. C, composite; $\mathrm{H}$, hybrid layer; $\mathrm{T}$, resin tags. It can be observed that there were more resin tags in the sample on which Nd:YAG laser was applied and the presence of resin tags with well-defined terminations in dentinal tubules.

Figure 5. Scanning electron micrograph of the bond interface of the specimen that received enamel treatment according to the manufacturer's instructions (Xeno III self-etch adhesive). C, composite; E, enamel; I, interface.

Figure 6. Scanning electron micrograph of the bond interface of the specimen that received enamel treatment according to the manufacturer's instructions (Xeno III self-etch adhesive) + Nd:YAG laser. C, composite; E, enamel; I, interface. It can be observed that there were no differences between the enamel-resin interface of the sample on which no irradiation was applied when compared with that of the sample that was irradiated. 
nonirradiated cavities, ${ }^{13,14}$ because Nd:YAG lasers promote denaturation of the organic components of dentin by heat generation, fusion, and recrystallization of the dentin surface, obliterating some dentinal tubules. ${ }^{13-16}$ These alterations in the morphology of the tooth substrate occur because of reduction in the percentage of calcium and phosphate in the dentin structure, causing changes in the organic composition of hydroxyapatite, leading to its recrystallization. ${ }^{16,17}$

Therefore, in the present study, the time when $\mathrm{Nd}$ :YAG laser was applied was changed to evaluate the influence of $\mathrm{Nd}$ :YAG laser after bond application and before light polymerization, a technique developed by Gonçalves and others. ${ }^{4}$

Gonçalves and others ${ }^{4}$ recommended Nd:YAG laser irradiation on dentin previously conditioned and impregnated with the adhesive system but before light polymerization. This technique would promote the development of a new substrate, in which dentin substrate and adhesive would be fused by the action of the laser. The development of this new substrate explains why all of the groups irradiated by laser in this study showed a substantial increase in bond strength. This is in agreement with Matos and others ${ }^{5}$ and Matos and others, ${ }^{6}$ who evaluated Nd:YAG irradiation before and after adhesive application and concluded that the best results were observed when laser was used after the adhesive system application. According to Dayem and others, ${ }^{18}$ treatment of the acid-etched dentin with Nd:YAG laser led to the significantly increased penetration depth of the adhesive bonding system into dentin.

After SEM analysis, the adhesive penetration in dentin showed fewer resinous tags in the specimen on which no irradiation was applied (Figure 3) compared with the sample that was irradiated with Nd:YAG laser (Figure 4). In addition, a new adhesive substrate composed of dentin tissue and adhesive system joined by the action of the laser was observed, as well as the presence of resin tags with welldefined terminations in dentinal tubules. ${ }^{4,19}$ The Nd:YAG laser treatment promoted more numerous tags and improved adhesive infiltration, probably producing a resistant substrate contributing to better bond strength. ${ }^{4,19}$

The representative SEM micrographs obtained from the enamel substrate generally showed that there was no difference between the enamel-resin interface in the sample on which no irradiation was applied (Figure 5) when compared with that of the sample that was irradiated (Figure 6). The energy density of $140 \mathrm{~mJ}$ used in this study seems to contribute to better interaction between the adhesive and enamel substrate.

With regard to failure mode analysis, it should be noted that the fracture was predominantly initiated at the interface between the composite and dentin or enamel substrate (adhesive or mixed failure), except in group X (Xeno III) without laser (control) in enamel, which showed an almost equal distribution between the four types of failure. This group showed the best bond strength results. Therefore, the type of treatment (presence or absence of Nd:YAG laser irradiation) was not able to alter the failure mode of composites bonded to enamel and dentin substrates.

The energy density of $140 \mathrm{~mJ}$ used in this study followed instructions of previous studies. Ribeiro and others ${ }^{20}$ observed the highest marginal microleakage results with this parameter, also using the technique of Nd:YAG laser irradiation after application of the adhesive However, future in vivo studies should be conducted to evaluate the thermal side effects of this technique, because Nd:YAG lasers have a high penetration depth that varies according to its parameters, so care should be taken not to overheat the pulp.

The results of the present study showed that the enamel samples subjected to laser irradiation presented the highest bond strength values, although the difference was not statistically significant when the enamel was not laser irradiated. In dentin, the irradiation with Nd:YAG laser significantly increased the bond strength values. Thus, further research is necessary to establish efficient and safe parameters.

\section{CONCLUSION}

Within the limitations of this study, it could be concluded that high bond strength values were found with enamel substrate both with Xeno III and Single Bond. It was also found that Nd:YAG laser significantly increased the bond strength to dentin substrate, although the difference in enamel was not statistically significant.

\section{Conflict of Interest}

The authors of this article certify that they have no proprietary, financial, or other personal interest of any nature or kind in any product, service, and/or company that is presented in this article.

(Accepted 31 August 2012) 


\section{REFERENCES}

1. Van Meerbeek B, De Munck J, Yoshida Y, Inoue S, Vargas M, Vijay P, Van Landuyt K, Lambrechts P, Vanherle G (2003) Buonocore memorial lecture. Adhesion to enamel and dentin: current status and future challenges Operative Dentistry 28(3) 215-235.

2. Peumans M, Kanumilli J, De Munck J, Van Landuyt K, Lambrechts P, \& Van Meerbeek B (2005) Clinical effectiveness of contemporary adhesives: a systematic review of current clinical trials Dental Material 21(9) 864-881.

3. Carvalho RM, Chersoni S, Frankenberger R, Pashley DH, Prati C, \& Tay FR (2005) A challenge to the conventional wisdom that simultaneous etching and resin infiltration always occurs in self-etch adhesives Biomaterials 26(9) 1035-1042.

4. Gonçalves SEP, Araújo MAM, Damião AJ (1999) Dentin bond strength: influence of laser irradiation, acid etching and hypermineralization Journal of Clinical Laser and Medical Surgery 17(2) 77-85.

5. Matos AB, Oliveira Dc, Kuramoto m, Eduardo CP, \& Matson E (1999) Nd:YAG laser influence on sound dentin bond strength Journal of Clinical Laser and Medical Surgery 17(4) 165-169.

6. Matos AB, Oliveira DC, Navarro RS, Eduardo CP, \& Matson E (2000) Nd:YAG laser influence on tensile bond strength of self-etching adhesive systems Journal of Clinical Laser and Medical Surgery 18(5) 253-257.

7. Tonami K, Takahashi H, Nakamura H, Motomura K, \& Nishimura F (1996) Effect of storage on tensile strength of bovine dentin Journal of Dental Research 75(Special Issue) 288. (Abstract 2161)

8. Pashley DH, Ciucchi B, Sano H, \& Horner JA (1993) Permeability of dentin to adhesive agents Quintessence International 24(9) 618-631.

9. Rosa BT, \& Perdigão J (2000) Bond strengths of nonrinsing adhesives Quintessence International 31(5) 353-358.

10. Miyazaki S, Iwasaki K, Onose H, \& Moore BK (2001) Enamel and dentin bond strengths of a single application bonding systems American Journal of Dentistry 14(6) 361-366.
11. Faria-E-Silva AL, Fabião MM, Sfalcin RA, de Souza Meneses M, Santos-Filho PC, Soares PV, \& Martins LR (2009) Bond strength of one-step adhesives under different substrate moisture conditions European Journal of Dentistry 3(4) 290-296.

12. Chaves CAL, de Melo RM, Passos SP, Camargo FP, Bottino MA, \& Balducci I (2009) Bond strength durability of self-etching adhesives and resin cements to dentin Journal of Application Oral Science 17(3) 155-160.

13. Ariyaratnam MT, Wilson MA, Mackie IC, \& Blinkhorn AS (1997) A comparison of surface roughness and composite/ enamel bond strength of human enamel following the application of the Nd:YAG laser and etching with phosphoric acid Dental Material 13(1) 51-55.

14. Ariyaratnam MT, Wilson MA, \& Blinkhorn AS (1999) An analysis of surface roughness, surface morphology and composite/dentin bond strength of human dentin following the application of the Nd:YAG laser Dental Material 15(4) 223-228.

15. Oda M, Oliveira DC, \& Liberti EA (2001) Morphological evaluation of the bonding between adhesive/composite resin and dentin irradiated with Er:YAG and Nd:YAG lasers: comparative study using scanning microscopy Brazilian Oral Research 15(4) 283-289

16. Kinney JH, Haupt DL, Balooch M, White JM, Bell WL, Marshall SJ, \& Marshall GW Jr (1996) The threshold effects of Nd and Ho:YAG laser-induced surface modification on demineralization of dentin surfaces Journal of Dental Research 75(6) 1388-1395.

17. Sazak H, Turkemen C, Gunday M (2001) Effects of $\mathrm{Nd}$ :YAG laser, air-abrasion and acid-etching on human enamel and dentin Operative Dentistry 26(5) 476-481.

18. Dayem RN (2010) Assessment of the penetration depth of dental adhesives through deproteinized acid-etched dentin using neodymium:yttrium-aluminum-garnet laser and sodium hypochlorite. Lasers in Medical Science 25(1) $17-24$

19. Franke M, Taylor AW, Lago A, \& Fredel MC (2006) Influence of Nd:YAG laser irradiation on an adhesive restorative procedure Operative Dentistry 31(5) 604-609.

20. Ribeiro CF, Anido AA, Rauscher FC, Yui KC, \& Gonçalves SE (2005) Marginal leakage in class V cavities pretreated with different laser energy densities Photomedicine and Laser Surgery 23(3) 313-316. 